\title{
Valedictory address
}

\author{
Janet Clarke
}

Janet Clarke was installed as President of the British Dental Association at last year's 2011 British Dental Conference and Exhibition held in Manchester. At this year's conference, also in Manchester, she gave the following valedictory address.

Ladies and Gentlemen, I have had a truly wonderful time as your President and I thank you most sincerely for honouring me in this way. I have had the pleasure of visiting many branches and sections, as well as invitations from a wide range of dental and non-dental organisations. I have had a memorable year and I have learnt a lot.

I have learnt that the role of President is greater than the individual holding the office; I have been made so welcome by everybody I have met and offered kind and generous hospitality. The Presidential medal is a lot like Dr Who's sonic screwdriver - it opens doors that otherwise would remain closed although thankfully I haven't then had to fight off hostile aliens or Daleks!

I have learnt that the BDA staff are even more committed, talented and hardworking than I had thought; they have supported me every inch of the way. The conference team is tremendous, the amount of work they do behind the scenes to ensure a successful, enjoyable and smooth running conference has to be seen to be believed. But this is not unique in the organisation, it is the norm and I think we should all be proud to belong to an organisation with such high quality staff. I pay particular tribute to Alison Magee, who not only has to cope with Peter, Susie and Stuart, but has managed my diary to ensure I arrive in the right place at the right time with the right kit. She has also taught me, ever so subtly, that its best to get the train or plane that arrives a good hour or two before you're supposed to speak, rather than my usual practice of thinking that 30 minutes is ample. This is going down well at home too...

I have learnt that the BDA finances are in extremely good hands - Richard Shilling, our Finance Director has resolutely refused to be moved by my frequent and I thought eloquent, pleas for a dress allowance. He looks after your money as if it were his own.

I have learnt that it is possible, by careful rotation and judicious dry cleaning, to make my three pre-existing cocktail dresses cope with a whole year of frequent engagements. This is also going down well at home...

More seriously, I have learnt that we are not alone, as dentists, in finding the burden of increasing regulation, red tape and policy uncertainty, difficult and frustrating. This has been echoed by others I have met working in the health field but also in business and commerce. The BDA works hard to build strategic alliances nationally and locally and we must continue to do so. When times are hard it is easy to look inwards and concentrate on our own challenges, but I think we must remember that we are not alone and there is strength in numbers.

And finally, I have learnt that even though we are in challenging times, the dentists and their teams that I have had the pleasure and privilege of meeting, are still extremely proud and positive about their practices and the clinical work they are able to provide for their patients. This has shone through from everyone I have spoken to and I think it's a credit to them, but also a credit to us as a profession. Their job satisfaction comes from providing a high quality service for their patients and having an excellent working relationship with their teams. This has made me proud to be a dentist, proud of our profession and proud to have represented our profession during the last year.

Now, I would like to be the first person to make an Olympic reference in this 2012 Conference and say that I am delighted to be handing the baton over to Frank Holloway as I know he will be an excellent ambassador for us and for the BDA. I have got to know Frank well over the past year or so; he has taken his forthcoming role very seriously and is a very organised, thoughtful and charming person. He is excellent and erudite company and I know he will enjoy travelling around the country and meeting as many people as possible. The President's medal will be in very safe hands.

DOI: 10.1038/sj.bdj.2012.371 